\title{
Study on the Translation of Political Texts from the Perspective of Eco-translatology---A Case Study on Xi Jinping: The Governance of China
}

\author{
Yanxia Hou, a , Huihong $\mathrm{Fu}^{2, \mathrm{~b}}$ \\ ${ }^{1}$ School of Foreign Languages, Nanchang Institute of Technology, Nanchang, 330099, China \\ ${ }^{2}$ School of Interpreting and Translation Studies, Guangdong University of Foreign Studies, Guangzhou, \\ 510420, China \\ aemail: hou_yanxia621@hotmail.com, bemail: fuhuihong_959@163.com
}

Keywords: Political texts; Eco-translatology; Translational Eco-environment; Eco-rationality

\begin{abstract}
As a new theory of translation with great interpretation capacity, Eco-translatology infuses fresh energy into the political texts translation. It put forward systematic theories and tactics from the Eco-environment angle and from the angle of the translator to guide the translation of political texts. This paper applied Eco-translatology into political text translation by taking $X i$ Jinping: the Governance of China as an example, which attempts to analyze the translation Eco-environment in English translation of Chinese political texts and the translator's role in process of translation and try to explore the translation methods from the ecological integrity, ecological aesthetics and diversity dimensions. Eco-translatology deems that it is translator's efforts to maintain the eco-rationality of the translation eco-environment, which provides a new research reference for the translation of political texts.
\end{abstract}

\section{Introduction}

In the trend of economic globalization and politics multi-polarization, China's reform and opening up and the socialist modernization drive have witnessed great achievements, and China's international status has improved. At the same time, China is more deeply integrated into the world. On the one hand, China is actively seeking the understanding and recognition of the international community. On the other hand, the whole world is looking to China for more understanding. Driven by this dual demand, China's translation has enjoyed dynamic growth. Among them, the English translation of political texts covers the development of China, the main tasks of the party, the basic policies and guidelines; therefore, first priority should been given to the political text translation[2].

Currently, Translation scholars at home and abroad adopt different translation strategies for the translation of political texts. The emergence of Eco-translatology provides a new perspective. It supplies systematic theories and methods to the translation of political texts from a macro perspective and from the perspective of the translator. Different from other translation theories, Eco-translatology advocates translation strategy does not rigidly adhere to the "literal translation or free translation" or "domestication or foreignization" but "the study of the translator's adaptation and selection" from the macroscopic ecological environment [8][9].

\section{Political texts}

On the whole, political texts are literature that directly or indirectly involved in political issues. They are composed of official texts, official script, publicity materials and political works. The political texts may cover all aspects of politics, culture and economy of a country. The political literature embraces "national fundamental policy document" and "the important speech of national leaders"[8]. It is a kind of political article characterized by rational discussion. This kind of text is often used to publicize the important thoughts of the party and state leaders, and expounds the route, guideline and policy of the party and the state.

Political texts are the most solemn and formal texts of the eternal publicity texts, with distinct 
characteristics of words and style. In light of the features of political texts, it is not difficult to see that the translation of political documents is not easy, especially in the process of avoiding Chinglish, dealing with the non-equivalence of words, explaining the implication of political terminology and overcoming the obstacles of information communication. On account of the diversities between Chinese and English cultural background, history, customs and other aspects, both of the two cultures embrace their own unique ways of expression, resulting in non-equivalence of information or disorder in the concept, connotation and significance of some words. Confronted with those difficulties, many researchers have tried to figure out new strategies and solutions.

\section{Eco-translatology}

In 2001, Professor Hu Gengshen, a PHD from Hong Kong Baptist University, firstly put forward the theory of translational adaptation and selection at the third Asian translators' forum. In the following years, Eco-translatology continued to flourish. It is an interdisciplinary study of ecology and translatology. Hu Gengshen in the Eco-translatology: construction and interpretation [7] stated, on the one hand, from the micro perspective, the ecological translation is to transplant one language ecosystem to another language ecological system; on the other hand, from the macro perspective, the ecological translation is to translate from the ecological perspective so as to obtain the harmonious ecological balance between translation acquisition and translation studies. It proves that the theory is based on the scientific principles, concepts and methods of ecology.

\subsection{Translation Eco-environment}

"Translation Eco-environment" refers to the world, which is composed of the original text, the source language and the target language, that is, the connection and interaction between language, communication, culture, society, as well as the author, the reader, the client, and so on. In recent years, the definition of "Translation Eco-environment" is more extensive, which refers to the text, the cultural context and the translation community, as well as the aggregation of the spirit and material. It can be said that all aspects except the translator can be regarded as the ecological environment of translation, and meanwhile, the translator is an integral part of the other's “Translation Eco-environment”[4].

\subsection{Eco-rationality}

Hu Gengshen[3][5]has generalized the eco-rationality of translation as follows: to pay attention to the integrity and relevancy, to stress the dynamic and equilibrium, to reflect the ecological aesthetics, to care for the translation community and to promote diversity and unity.

The so-called "pay attention to the integrity and relevancy" is when we study the translation eco-system, following the eco-rationality principle, we cannot just be confined to a sub-ecological system (such as the ontology, ecosystem) or a certain stakeholder. From the perspective of eco-rationality, we need to take care of the correlation and integrity among different ecosystems.

The embodiment of ecological aesthetics is that the translator should comply with the eco-rationality and attach great importance to the pursuit of beauty, always paying attention to the aesthetic elements and ecological aesthetic principles such as "symmetry", "balance”, "order" and "rhythm", either in the macro or micro level in the process of translation study.

"Stressing dynamic and equilibrium" indicates that when the translators conduct translation activities, they should follow the eco-rationality to form a dynamic and balanced eco-system of translation with ecological interdependence by focusing on the interaction and interplay between the subject and object, the subject and external environment.

\section{Analysis of Xi Jinping: the Governance of China in light of Eco-translatology}

Xi Jinping: the Governance of China aims to introduce China's ruling policy and governance conception to the international community. It is not only an important window through which the international community can have a better understanding of the concept of China's idea of 
development, governance policies and strategies, but also a representative of the classical Chinese government political literature. This part will focus on the macro and micro ecological environment of the translation of political texts, and measure the quality of the translation from a multi-dimensional perspective, which will provide the strategies and approaches for the translation of political texts.

\subsection{Analysis of Translation Eco-environment}

Broadly speaking, Eco-environment is related to the macro environment of politics, economy and culture in the world, while specifically, it indicates the entirety of the original text, the source language and the target language system. Macro Eco-environment of political texts will firstly be analyzed to have an overall picture of the whole environment, then concentration will be switched to the micro Eco-environment of Xi Jinping: the Governance of China.

\subsubsection{Macro Eco-environment of Political Texts Translation}

Since China's reform and opening up, the international community has marveled at the great achievements made by China, and has begun to emulate China's national governance principles and policies. Consequently, a friendly political texts translation environment has emerged. The macro Eco-environment of political texts consists of two parts: the source language Eco-environment and the target language Eco-environment. The macro Eco-environment of political texts translation is being bettered and optimized, which is due to the efforts made by the two parties at home and abroad.

In the first place, China's domestic translation scholars and related personnel have improved their ideology of political literature. The political texts translation attaches more importance to the audience-centered principle, which is helpful for the audiences in different Eco-environment to better their understanding of and accept the content of Chinese political texts. In the second place, foreign counterparts tend to have a deep knowledge of china. Learning about China has swept the globe like a raging fire, which makes a difference in the distinct reduction of the "common sense interpretation" in the translation of political documents[11].

\subsubsection{Micro Eco-environment of Xi Jinping: the Governance of China}

This book is co-edited by the State Council Information Office, the Central Literature Research Center and CIPG, and is published by the Foreign Language Press. The book enjoys immense popularity and often presents as a national gift to foreign guests. In the micro Eco-environment of the book, the translator and the reader play the main role, and the translator is the centerpiece in that the translator needs to decide how to reach the eco-rationality in the big environment.

The reader is one of the most important constraints of the micro eco-environment, which requires the translator equips himself with high degree of political consciousness and good understanding of national policies and regulations. In the translation process, the translator shall precisely comprehend the intention of the leaders, convey the spirit and avoid ambiguity. Many of the readers of the book are influential figures such as the leaders of states who are able to affect the international situation. Therefore, the translation should be devoid of any deviation; otherwise, the consequences may be very serious, even threat the international status and image of China[11].

\subsection{Analysis of Eco-rationality}

The principle of "eco-rationality" is also one of the criteria to judge the quality of translation. It attaches great importance to whether the translation has reached the best balance point and realized the ecological harmony. The main focus points of eco-rationality are "integrity and relevancy", “ecological aesthetics” and "dynamic and equilibrium”[6].

\subsubsection{Integrity and relevancy}

Eco-rationality makes a great emphasis on the integration and the overall development of ecosystems in the process of translation. In accordance with the needs of eco-rationality, the translator will comprehensively translate all kinds of related affairs, focusing on translation integrity 
and relevancy.

And the first problem that the translator confronts in the process of translation is language. The integrity and relevancy requires that the translator should adapt to the linguistic ecology of the source language and the target language, have an intimate bilingual knowledge of the linguistic features of the source and target language and the language preference of the source and target language readers.

Xi Jinping: the Governance of China is mainly collected President Xi's speech. Although compiled into a book, it is still in the form of speech presentation. In consequence, this book is short and colloquial but terse and forceful with classical citations. To ensure the integrity and relevance of the translation ecosystems, it is necessary to focus on vocabulary, syntax and style etc.

Example 1[10]:

English version: We should be guided by the strategic thinking that only development will make a difference.

"Only development will make a difference" vividly illustrates the importance of "development" for China's reform and opening up. Translators adopt literal translation, and translate the word with strong Chinese characteristics of political neologisms as "make a difference". Therefore, the translation has lived up to the two basic requirements the translation of political texts of both following closely the original and being accessible to the target readers.

Example 2 [10]:

English version: While studying the document, we should not stop at the surface, quote it out of context, copy it mechanically or apply it blindly.

Chinese discourse is fond of employing four-character idioms, which is the typical example of culture's influence on speech production. However, English language strives for clear expression, very sensitive to logical confusion and text stack. In order to facilitate the understanding of the readers, the English translation breaks the four-character structure, and changes it into the English type[1]. It extracts the actual content from the gorgeous language shell and grasps the essence of semantics.

As for one title in the book, "Ge Ming"is a noun in the original text. The translation of the title is Revolutionize Energy Production and Consumption. "revolutionize", as a verb, is a flexible translation. And in another title, "Fang Fei Meng Xiang" means the dream comes true. However, in English culture, there is no such concept. Here if the word "Fang Fei" is ponderously transferred into the English translation, foreign readers will be confused; Thus, the translation Realize Youthful Dreams is clear and accurate, achieving a precise integrity and relevancy of the language ecosystems.

From the above examples we can observe that the translation eco-environment is divided into explicit and implicit parts. This is also the difference between English and Chinese, English content tends to be manifest, while Chinese attaches importance to the infinite significance. The most basic part of integrity and relevancy is the conversion of meaning. However, it is not only to simply express the same words in different languages, but to seize the meaning of the word.

\subsubsection{Ecological aesthetics}

As mentioned above, the principle of ecological aesthetics requires translators to pay attention to such elements as "symmetry", "rhythm”, “order” and so on. Since Chinese culture is extensive and profound with a long history, Chinese is very particular about beauty. Both poetry and prose reflect a kind of symmetrical beauty, and strive to be vivid and expressive. Therefore, when translating the political texts, the translator should pay attention to the aesthetic sense of translation, especially when it comes to related Chinese cultural verses or words.

Example 1 [10]:

English version: We must have confidence in our path, our theory and our system. We must be as tenacious as bamboo, as described by Zheng Xie: "In the face of all blows, not bending low, it still stands fast. Whether from east, west, south, or north the wind doth blast."

"In the face of all blows, not bending low, it still stands fast. Whether from east, west, south, or 
north the wind doth blast" is the verse of one poem. Our government leaders are fond of quoting ancient Chinese poems or phrases in their statements. And how to deliver the meaning of those poems clearly and skillfully is one of the difficulties for the translator. In the translation "In the face of all blows, not bending low, it still stands fast. Whether from east, west, south, or north the wind doth blast.", "fast" and "blast" are rhymed, which shows that the translators are trying to maintain the ecological asthetics.

Exmaple 2 [10]:

English version: Winning or losing public support is vital to the Party's survival or extinction. The Party must dedicate its soul and mind to the people, share their weal and woe, and rely on them to continue to make progress. Only then "steadfastly we stand our ground" against "ominous storms that threaten to engulf us."

When translating Chinese phrase "Sheng Si Cun Wang”, we do not have to translate it word by word. The translation is "survival or extinction", which considers from the symmetry. As for "Xin Lian Xin, Tong Hu Xi, Gong Ming Yun”, the translator just grasps the essence of the meaning and translates the phrase as "dedicate its soul and mind to the people, share their weal and woe". "Weal and woe" adopts the English rhetoric-alliteration to make a special effect. From the perspective of ecological aesthetics, they are translated as "steadfastly we stand our ground" against "ominous storms that threaten to engulf us." From "stand and ground", "storms and us", we can see that the translators rhyme the "d" and "s".

\subsubsection{Dynamic and Equilibrium}

The translation of political texts is aimed at publicity, that is to say, communication. The translator should pay attention to whether the translation delivers the dynamic and equilibrium. And in the process of translating the book Xi Jinping: the Governance of China, the translator should pay attention to whether the translation conforms to the reading habits of readers, and as far as possible to let the readers get the same information of the original readers to achieve the dynamic and equilibrium.

Example 1[10]:

English version: We know keenly that reform and opening up is an ongoing process that we will never stop. China's reform has entered a deep water zone, where problems crying to be resolved are all difficult ones.

Without contexts, Chinese expressions “Jin Xing Shi” and "Wan Cheng Shi” are grammatical terms in English learning. Here if the sentence is translated as "Reform has no perfect tense, but only progressive tense", in fact, foreign readers can understand it. However, dynamic and equilibrium think highly of the balance between the translator and the reader. The translation by the translator is "Reform and opening up is always ongoing and will never end", which is apparently better than the first translation. In English, perfect tense and progressive tense themselves contain the meanings that have ingrained in the mind of English readers. Therefore, if they are applied to describe the reform and opening up, it would be a little far-fetched.

Example 2 [10]:

English version: If the "Belt and Road" are likened to the two wings of a soaring Asia, then connectivity is like their arteries and veins.

Here, four-character words "Yi Dai Yi Lu"and "Hu Lian Hu Tong” are typical Chinese style of antithesis, which exactly test the translator ability. And at the same time, we have to focus on the reader. "Xue Mai Jing Luo" is also a word with the Chinese characteristics. Since foreigners do not figure it out, the translator prefers to simple translation. Moreover, "Xue Mai Jing Luo" in the Chinese language itself is also lack of substantial meaning, that is, it is a rhythmical four-character word.

It is because of the focus on the three principles--- "integrity and relevancy", "ecological aesthetics" and "dynamic and equilibrium" that eco-rationality has become the macro guidance idea of the construction of Eco-translatology discourse system. Eco-rationality not only focuses on the combination and unification of the analysis and synthesis, but also the influence and restriction of 
translation eco-environment on translator's behaviors; it both stresses the coordination among "translation studies", "translation theories" and "translation texts" and the pursuit of the integration and development of "translator", "text” and "environment”.

\section{Conclusion}

Eco-translatology is of great significance to the translation of political texts. As a form of translation theory in the postmodern context, Eco-translatology is a kind of interdisciplinary and multidisciplinary product, as well as the extension and transformation of contemporary translation theory, a reflection of the development trend of translation from the traditional single subject to the contemporary interdisciplinary integration.

By taking of Xi Jinping: the Governance of China as a case study, the authors validate the guidance and adaptability of Eco-translatology theory to the translation of political texts, and the role it plays in the improvement of the Chinese political document translation quality, in consequence, to provide reference for future research on the translation of political texts. In addition, the research will pave the way for future political texts translation.

\section{Acknowledgement}

This paper is a part of the research "English Translation of Vocabulary with Chinese Characteristics from the Perspective of Eco-Translatology_ A Case Study on Xi Jinping: the Governance of China”, Humanities and Social Science Research Project sponsored by Educational Commission of Jiangxi Province (Project No. YY1542).

\section{References}

[1] Bassnett, S. \& A. Lefevere. Translation, History and Culture[M]. Shanghai: Shanghai Foreign Language Education Press, 2010.

[2] Cronin Michael. Translation and Globalization[M]. London: Roultledge, 2003.

[3] Hu Gengshen.On Fu Lei's Translation Philosophies: An Eco-translatological Perspective[J]. Journal of Foreign Languages, 2009(2): 47-53.

[4] Hu Gengshen.Interpretation of Eco-translatology[J].Chinese Translators Journal,2008(6): 11-15.

[5] Hu Gengshen. Eco-translatology: Background and Foundation for Development[J]. Foreign Languages Research, 2010(4):62-67+112.

[6] Hu Gengshen.The Research Focus and Theoretical Perspectives of Eco-translatology[J]. Chinese Translators Journal, 2011(2):5-9.

[7] Hu Gengshen. Eco-translatology-Construction \& Interpretation [M]. Beijing: The Commercial Press, 2013.

[8] Jia Wenbo. Translation Strategies of Text Type-Reflection on the Discussion of Domestication or Foreignization[J].Shanghai Journal of Translators for Science and Technology, 2004(3):6-11.

[9] Liu Yafeng. Translator's Adaptation and Selection-The Study of Publicity Translation[M]. Beijing: The Chinese People’s Publishing House, 2010.

[10] Xi Jinping. Xi Jinping: The Governance of China [M]. Beijing: Foreign Languages Press, 2014.

[11] Zhang Kaige. Translation Strategies of Political Texts: In the Light of Eco-translatology---A Case Study on Xi Jinping: the Governance of China[D].Beijing Foreign Studies University, 2015. 